\title{
Changes in Obesity Odds Ratio among Iranian Adults, since 2000: Quadratic Inference Functions Method
}

\author{
Enayatollah Bakhshi, ${ }^{1}$ Koorosh Etemad, ${ }^{2}$ Behjat Seifi, ${ }^{3}$ Kazem Mohammad, \\ Akbar Biglarian, ${ }^{1}$ and Jalil Koohpayehzadeh ${ }^{2}$ \\ ${ }^{1}$ Department of Biostatistics, University of Social Welfare and Rehabilitation Sciences, Tehran, Iran \\ ${ }^{2}$ Center for Diseases Control, Ministry of Health and Medical Education, Tehran, Iran \\ ${ }^{3}$ Department of Physiology, Medicine School, Tehran University of Medical Sciences, Tehran, Iran \\ ${ }^{4}$ Department of Biostatistics, School of Public Health and Institute of Public Health Research, \\ Tehran University of Medical Sciences, Tehran, Iran \\ Correspondence should be addressed to Enayatollah Bakhshi; bakhshi@razi.tums.ac.ir
}

Received 19 April 2016; Accepted 14 September 2016

Academic Editor: Ezequiel López-Rubio

Copyright (C) 2016 Enayatollah Bakhshi et al. This is an open access article distributed under the Creative Commons Attribution License, which permits unrestricted use, distribution, and reproduction in any medium, provided the original work is properly cited.

\begin{abstract}
Background. Monitoring changes in obesity prevalence by risk factors is relevant to public health programs that focus on reducing or preventing obesity. The purpose of this paper was to study trends in obesity odds ratios (ORs) for individuals aged 20 years and older in Iran by using a new statistical methodology. Methods. Data collected by the National Surveys in Iran, from 2000 through 2011. Since responses of the member of each cluster are correlated, the quadratic inference functions (QIF) method was used to model the relationship between the odds of obesity and risk factors. Results. During the study period, the prevalence rate of obesity increased from $12 \%$ to $22 \%$. By using QIF method and a model selection criterion for performing stepwise regression analysis, we found that while obesity prevalence generally increased in both sexes, all ages, all employment, residence, and smoking levels, it seems to have changes in obesity ORs since 2000. Conclusions. Because obesity is one of the main risk factors for many diseases, awareness of the differences by factors allows development of targets for prevention and early intervention.
\end{abstract}

\section{Background}

Obesity has become a growing serious health problem in all regions of the world and is linked to increased risk of cardiovascular diseases [1-4], diabetes [5], chronic pain [6], arthritis [7], asthma [8], Alzheimer's disease [9], and functional impairment [10] and so it can affect a person's quality of life. Since 1980, obesity has more than doubled in the world and studies showed the association with higher mortality [11]. In 2014, more than 600 million of world's population and, specifically, $13 \%$ of adults aged 18 and over were obese [12]. In 2014, more than $36 \%$ of US adults were obese. The prevalence of obesity increased among US adults and youth from 1998 through 2014. However, there was no significant change from 2003-2004 to 2013-2014 in obesity among the youth, and the prevalence of obesity remains high [13]. In Canada, the prevalence of obesity among adults increased 200\% (from 6.1\% to 18.3\%) between 1985 and 2011 [14]. Results from the Australian Health Survey (2011-12) showed that almost $28 \%$ of the population aged 18 and over were obese. In England, the obesity prevalence among adults rose from $14.9 \%$ to $25.6 \%$ from 1993 through 2014 [15].

The relationship between obesity and various factors was explored. Potential predictors could be age and sex [16]. Another potential confounder of this association in adults includes the socioeconomic status [17]. Significant association between obesity and place of residence was observed in studies $[18,19]$. The association of obesity with lifestyle habits such as smoking has been analyzed in some studies [20].

Monitoring changes in obesity prevalence by risk factors is relevant for public health programs that focus on reducing or preventing obesity. There is no study to explore changes 
in obesity ORs for related factors in Iranian adults. The purpose of this paper was to study trends in obesity ORs for individuals aged 20 years and older in Iran.

\section{Methods}

\subsection{Data}

2.1.1. NHSI 2000. The National Health Survey in Iran (NHSI) was designed by the Iranian Ministry of Health and Medical Education to determine related factors with public health. Targeted population was all Iranian citizens. Household was defined as those living in the same residence, participating in the households expenses and usually eating together. Any individual living single was also considered a household. Cluster method was the sampling way, 8 households in each. This number for the cluster size was based on oneday performance capacity of the data collection group: four persons ( 2 physicians, 1 interviewer, and 1 lab technician). The information about households was achieved from the Family Questionnaire during an in-home interview [21, 22]. The NHSI data used in this analysis included 27869 participants aged +20 years.

2.1.2. WHO Step Surveys 2007-2011. The WHO STEPwise approach to Surveillance (STEPS) is a simple, standardized method for collecting, analyzing, and disseminating data in WHO member countries. To compare between WHO member countries, the same standardized questions were used [23].

This survey in Iran was also conducted under the supervision of $\mathrm{WHO}$ and approved by the ethics committee of the Center for Disease Management located in the Iranian Ministry of Health and Medical Education. Representative data for adults aged $\geq 15$ was achieved by cluster sampling method and in collaboration with 31 Iranian medical schools. The number of clusters in each province was proportional to the size of that province, with each cluster including 10 men and 10 women. Step surveys data included 26716, 20917, and 8425 participants aged +20 years from 2007,2009 , and 2011 , respectively.

Pregnant women were excluded from the analyses.

\section{Measurements}

3.1. Response Variable. For all four surveys, height and weight were actually measured rather than self-reported. Height was measured without shoes to the nearest $5 \mathrm{~mm}$. Weight was measured to the nearest $0.1 \mathrm{~kg}$ with the subject in light indoor clothes, with emptied pockets and without shoes. BMI (body mass index) was calculated as weight in kilograms divided by height in meters squared, and obesity was defined as BMI of 30.0 or higher.

3.2. Independent Variables. For state comparisons between all four studies, we limited independent variables to age, sex, place of residence, employment, and smoking status.
Information about the respondents' age was based on their self-reported birth year, and subjects were stratified into five 10-year age groups (20-29, 30-39, 40-49, 50-59, and +60 years). The subjects were grouped according to their place of residence as living in cities (urban) or villages (rural). Employment status was analyzed as three categorical variables (public employed/private employed/other (student, retired, home maker, unable to work, soldier, and others)). Smoking status was dichotomized into smoker versus nonsmoker.

3.3. Statistical Analysis. Logistic regression has become a popular approach for analyzing binary data. It is a common characteristic of such method that observations can be assumed to be statistically independent. Since responses in the same cluster are typically more similar than responses from different clusters, the analytic approach for modeling this type of data is generalized estimating equations (GEE) method, which takes intracluster correlation into account rather than assuming independency. Selection of a working correlation structure is at the discretion of the researcher. However, a misspecified working correlation structure affects efficiency [24].

The quadratic inference functions (QIF) method proposed by $\mathrm{Qu}$ et al. [25] is alternative to the GEE approach, which enables us to do goodness-of-fit tests and model selection [26]. We applied QIF method to assess the association between obesity and all other factors. All analyses were carried out by using the SAS software package. The results are presented as the odds ratios and their 95\% confidence intervals (CIs).

3.4. QIF Method. A common assumption for GEE is that the outcomes from different clusters are independent and within clusters are dependent. Let $Y_{i j}$ be the binary response and let $X_{i j}$ be a vector of covariates from the $j$ th individual in the $i$ th cluster, for $K$ clusters. The GEE model has two parts: (i) the marginal mean $\mu_{i j}$ is considered as a function of the covariates through a link function $g$ with $g\left(\mu_{i j}\right)=g\left(E\left(Y_{i j} \mid\right.\right.$ $\left.\left.X_{i j}\right)\right)=X_{i j}^{\prime} \beta$; and (ii) the variance of $\mu_{i j}$ is a function of the mean $\operatorname{Var}\left(Y_{i j} \mid X_{i j}\right)=\varphi V\left(\mu_{i j}\right)$, where $\varphi$ is a scalar parameter. The basis of quasi-likelihood estimation is that the entire distribution of the responses is not needed, and the equations are completely specified by the mean and variance of the random response. The GEE estimator $\beta$ is the solution of these equations:

$$
\sum_{i}\left(\frac{\partial \mu_{i}}{\partial \beta}\right)^{\prime}\left(D_{i}^{1 / 2} R_{i}(\alpha) D_{i}^{1 / 2}\right)^{-1}\left(y_{i}-\mu_{i}\right)=0
$$

$D_{i}$ is the diagonal matrix of the marginal variances, and $R_{i}(\alpha)$ is the working correlation matrix.

In QIF method, we consider the inverse of working correlation structure as a linear combination of several basic matrices:

$$
R^{-1} \approx a_{0} I+a_{1} M_{1}+\cdots+a_{k} M_{k},
$$

where $M_{0}$ is the identity matrix and $M_{i}$ are known basis matrices. While determining that a working correlation 
TABLE 1: Descriptive prevalence of obesity across study variable levels in the four studies.

\begin{tabular}{|c|c|c|c|c|c|c|c|c|c|c|c|c|}
\hline \multirow{2}{*}{ Variable } & \multicolumn{3}{|c|}{2000} & \multicolumn{3}{|c|}{2007} & \multicolumn{3}{|c|}{2009} & \multicolumn{3}{|c|}{2011} \\
\hline & Rate $^{\mathrm{a}}$ & $\%$ & Total & No & $\%$ & Total & No & $\%$ & Total & No & $\%$ & Total \\
\hline \multicolumn{13}{|l|}{ Age } \\
\hline $20-30$ & 556 & 6.4 & 8674 & 600 & 9.7 & 6160 & 493 & 9.4 & 5226 & 263 & 10.5 & 2500 \\
\hline $30-40$ & 969 & 13.6 & 7115 & 1214 & 20.5 & 5922 & 908 & 19.4 & 4671 & 354 & 21.2 & 1666 \\
\hline $40-50$ & 906 & 18.3 & 4948 & 1578 & 26.1 & 6047 & 1222 & 26.6 & 4599 & 423 & 31.1 & 1361 \\
\hline $50-60$ & 496 & 18.0 & 2753 & 1551 & 25.6 & 6050 & 1201 & 25.7 & 4676 & 592 & 29.4 & 2017 \\
\hline $60+$ & 491 & 11.2 & 4379 & 603 & 23.8 & 2537 & 409 & 23.4 & 1745 & 246 & 27.9 & 881 \\
\hline \multicolumn{13}{|l|}{ Sex } \\
\hline Men & 832 & 6.6 & 12690 & 1698 & 12.9 & 13194 & 1235 & 12.2 & 10083 & 520 & 14.6 & 3551 \\
\hline Women & 2586 & 17 & 15179 & 3848 & 28.5 & 13522 & 1998 & 27.7 & 10834 & 1358 & 27.9 & 4874 \\
\hline \multicolumn{13}{|l|}{ Place of residence } \\
\hline Rural & 785 & 8.0 & 9833 & 1807 & 16.5 & 10920 & 1503 & 16.9 & 8909 & 457 & 18.4 & 2478 \\
\hline Urban & 2633 & 14.6 & 18036 & 3739 & 23.7 & 15796 & 2730 & 22.7 & 12008 & 1421 & 23.9 & 5947 \\
\hline \multicolumn{13}{|l|}{ Employment status } \\
\hline Other & 2574 & 16.0 & 16123 & 4117 & 25.1 & 16370 & 3916 & 20.9 & 18705 & 1370 & 29.5 & 4648 \\
\hline Public employed & 239 & 8.7 & 2741 & 369 & 15.8 & 2331 & 246 & 15.6 & 1574 & 166 & 11.4 & 1457 \\
\hline Private employed & 605 & 6.7 & 9005 & 1060 & 13.2 & 8015 & 71 & 11.1 & 638 & 342 & 14.7 & 2320 \\
\hline \multicolumn{13}{|l|}{ Smoking status } \\
\hline Nonsmoker & 3175 & 13.3 & 23821 & 4819 & 22.9 & 21076 & 3827 & 21.7 & 17629 & 1728 & 23.9 & 7228 \\
\hline Current smoker & 243 & 6.0 & 4048 & 727 & 12.9 & 5640 & 406 & 12.3 & 3288 & 150 & 12.5 & 1197 \\
\hline Total & 3418 & 12 & 27869 & 5546 & 20 & 26716 & 4233 & 20 & 20917 & 1878 & 22 & 8425 \\
\hline
\end{tabular}

${ }^{a}$ Prevalence of obesity.

structure is difficult, we can also select a hybrid working correlation by combining basic matrices from several working correlations [27].

Substitute (2) into (1) and rearrange slightly to obtain

$$
\begin{aligned}
\bar{g}_{K}(\beta) & =\frac{1}{K} \sum_{i}^{K} g_{i}(\beta) \\
& \approx \frac{1}{K}\left[\begin{array}{c}
\sum_{i}\left(\frac{\partial \mu_{i}}{\partial \beta}\right)^{\prime}\left(D_{i}\right)^{-1}\left(y_{i}-\mu_{i}\right) \\
\sum_{i}\left(\frac{\partial \mu_{i}}{\partial \beta}\right)^{\prime}\left(D_{i}^{-1 / 2} M_{1} D_{i}^{-1 / 2}\right)\left(y_{i}-\mu_{i}\right) \\
\vdots \\
\sum_{i}\left(\frac{\partial \mu_{i}}{\partial \beta}\right)^{\prime}\left(D_{i}^{-1 / 2} M_{m} D_{i}^{-1 / 2}\right)\left(y_{i}-\mu_{i}\right)
\end{array}\right] .
\end{aligned}
$$

That is, (1) takes the form of $K\left(a_{0}, a_{1}, \ldots, a_{m}\right)^{\prime} \bar{g}_{K}(\beta)$. It is a problem to solve it for $\beta$, because the number of equations is greater than the number of parameters. By using generalized method of moments [27], we can minimize the QIF:

$$
\begin{aligned}
& \operatorname{QIF}_{K}(\beta) \\
& \quad=K \bar{g}_{K}(\beta)\left(K^{-1} \sum_{i}^{K} g_{i}(\beta) g_{i}^{\prime}(\beta)\right)^{-1} \bar{g}_{K}(\beta) .
\end{aligned}
$$

Note that the $\operatorname{QIF}_{K}(\beta)$ contain only the regression parameter $\beta$ and the basis matrices $M_{i}$.

\section{Results}

We estimated 2000 to 2011 trends in the prevalence of obesity by sex, age, place of residence, employment, and smoking status for Iranian population.

Table 1 provides the estimated obesity prevalence rates for the Iranian adults from the four data sources. Not surprisingly, the prevalence of obesity nearly doubled from $12 \%$ in 2000 to $20 \%$ in 2007 and rose slightly to $22 \%$ between 2009 and 2011, and the prevalence of obesity remains high. From 2000 to 2011, increases in obesity among Iranian adults continue in both sexes, all ages, all employment levels, both places of residence levels, and both smoking levels.

Table 2 shows the OR (odds ratio) of the QIF regression method for 2000, 2007, 2009, and 2011 data. In all four surveys, obesity was significantly associated with age, sex, place of residence, employment levels, and smoking status.

Using age group 20-30 years as the reference, obesity ORs for 30-40 were 2.44 (95\% CI 2.18 to 2.72 ), 2.61 (95\% CI 3.35 to 2.91 ), 2.42 (95\% CI 2.14 to 2.72 ), and 2.16 (95\% CI 2.81 to 2.59 ) in 2003, 2007, 2009, and 2011, respectively; obesity ORs for $40-50$ years were 3.52 (95\% CI 3.13 to 3.94$)$, 3.66 (95\% CI 3.30 to 4.06 ), 3.74 (95\% CI 3.23 to 4.20 ), and 3.41 (95\% CI 2.86 to 4.08 ) in 2003, 2007, 2009, and 2011, respectively; obesity ORs for $50-60$ were 3.40 (95\% CI 2.98 to 3.88 ), 3.52 (95\% CI 3.17 to 3.90 ), 3.52 (95\% CI 13 to 3.94 ), and 3.25 (95\% CI 2.74 to 3.86 ) in 2003, 2007, 2009, and 2011, respectively; obesity ORs for $60+$ years were 3.02 (95\% CI 1.78 to 2.31), 3.25 (95\% CI 2.86 to 3.69 ), 3.15 (95\% CI 2.72 to 3.65), and 2.82 (95\% CI 2.29 to $3.46)$ in 2003, 2007, 2009, and 2011, respectively. 
TABLE 2: Adjusted ${ }^{a}$ obesity odds ratios in four surveys of Iranian adults.

\begin{tabular}{|c|c|c|c|c|c|c|c|c|}
\hline \multirow{2}{*}{ Variable } & \multicolumn{2}{|c|}{2000} & \multicolumn{2}{|c|}{2007} & \multicolumn{2}{|c|}{2009} & \multicolumn{2}{|c|}{2011} \\
\hline & $\mathrm{OR}^{\mathrm{b}}$ & $95 \% \mathrm{CI}^{\mathrm{c}}$ & $\mathrm{OR}^{\mathrm{b}}$ & $95 \% \mathrm{CI}^{\mathrm{c}}$ & $\mathrm{OR}^{\mathrm{b}}$ & $95 \% \mathrm{CI}^{\mathrm{c}}$ & $\mathrm{OR}^{\mathrm{b}}$ & $95 \% \mathrm{CI}^{\mathrm{c}}$ \\
\hline \multicolumn{9}{|l|}{ Age } \\
\hline $20-30$ & 1.00 & & 1.00 & & 1.00 & & 1.00 & \\
\hline $30-40$ & 2.44 & $2.18-2.72$ & 2.61 & $2.35-2.91$ & 2.42 & $2.14-2.72$ & 2.16 & $1.81-2.59$ \\
\hline $40-50$ & 3.52 & $3.13-3.94$ & 3.66 & $3.30-4.06$ & 3.74 & $3.23-4.20$ & 3.41 & $2.86-4.08$ \\
\hline $50-60$ & 3.40 & $2.98-3.88$ & 3.52 & $3.17-3.90$ & 3.52 & $3.13-3.94$ & 3.25 & $2.74-3.86$ \\
\hline $60+$ & 3.02 & $1.78-2.31$ & 3.25 & $2.86-3.69$ & 3.15 & $2.72-3.65$ & 2.82 & $2.29-3.46$ \\
\hline \multicolumn{9}{|l|}{ Sex } \\
\hline Men & 1.00 & & 1.00 & & 1.00 & & 1.00 & \\
\hline Women & 2.40 & $2.10-2.74$ & 2.35 & $2.15-2.58$ & 2.57 & $2.36-2.79$ & 1.58 & $1.34-1.85$ \\
\hline \multicolumn{9}{|l|}{ Place of residence } \\
\hline Rural & 1.00 & & 1.00 & & 1.00 & & 1.00 & \\
\hline Urban & 1.98 & $1.81-2.16$ & 1.63 & $1.53-1.74$ & 1.49 & $1.39-1.61$ & 1.46 & $1.29-1.65$ \\
\hline \multicolumn{9}{|l|}{ Employment status } \\
\hline Other & 1.00 & & 1.00 & & 1.00 & & 1.00 & \\
\hline Public employed & 0.72 & $0.61-0.84$ & 0.76 & $0.67-0.87$ & 0.74 & $0.58-0.96$ & 0.55 & $0.45-0.67$ \\
\hline Private employed & 0.84 & $0.73-0.97$ & 0.93 & $0.84-1.02$ & 0.82 & $0.70-0.95$ & 0.77 & $0.64-0.92$ \\
\hline \multicolumn{9}{|l|}{ Smoking status } \\
\hline Nonsmoker & 1.00 & & 1.00 & & 1.00 & & 1.00 & \\
\hline Current smoker & 0.65 & $0.56-0.76$ & 0.69 & $0.63-0.77$ & 0.77 & $0.68-0.88$ & 0.57 & $0.46-0.69$ \\
\hline
\end{tabular}

Compared with male, obesity ORs for female were 2.40 (95\% CI 2.10 to 2.74 ), 2.35 (95\% CI 2.15 to 2.58 ), 2.57 (95\% CI 2.36 to 2.79 ), and 1.58 (95\% CI 1.34 to 1.85 ) in 2003, 2007, 2009, and 2011, respectively. Obesity ORs for urban adults were 1.98 (95\% CI 1.81 to 2.16), 1.63 (95\% CI 1.53 to 1.74 ), 1.49 (95\% CI 1.39 to 1.61 ), and 1.46 (95\% CI 1.29 to 1.65 ) in 2003 , 2007, 2009, and 2011, respectively. Obesity ORs for public employed people were 0.72 (95\% CI 0.61 to 0.84$), 0.76$ (95\% CI 0.67 to 0.87 ), 0.82 (95\% CI 0.70 to 0.95 ), and 0.55 ( $95 \%$ CI 0.45 to 0.67$)$ in $2003,2007,2009$, and 2011 respectively; obesity ORs for private employed people were 0.84 (95\% CI 0.73 to 0.97 ), 0.93 (95\% CI 0.84 to 1.02 ), 0.74 (95\% CI 0.58 to 0.965 ), and 0.77 (95\% CI 0.64 to 0.92 ) in 2003, 2007, 2009, and 2011, respectively, compared with others. Compared with nonsmokers, obesity ORs for smokers were 0.65 (95\% CI 0.56 to 0.76 ), 0.69 (95\% CI 0.63 to 0.77 ), 0.77 (95\% CI 0.68 to 0.88 ), and 0.57 (95\% CI 0.46 to 0.69$)$ in $2003,2007,2009$, and 2011, respectively.

\section{Discussion}

In almost ten-year period from 2000 to 2011, the prevalence of obesity among Iranian adults doubled. Precisely, trends in obesity prevalence show alarming increase among adults from 2000 through 2007 but slow increase from 2007 through 2011. From 2000 to 2007, the prevalence of obesity in adults has jumped markedly in all age groups, both men and women, all employment levels, both places of residence levels, and both smoking levels (Figure 1(a)).
Similar to some studies [28-33], our results showed positive association between age and obesity. With progression of age, there are changes in food intake, energy expenditure, and appetite and body composition in addition to bone and muscle losses that influence the body composition. Although fat-free mass (FFM) progressively decreases after the age of 30 , fat mass increases. FFM decreases by up to $40 \%$ from the age of 20 to 70 primarily to skeletal muscle. However, FFM reaches its peak at the age of 20-30 years; the maximal fat mass is usually gained at the age of 60-70. Both kinds of fats subsequently decline after this age. Overall, our findings also show a continuing decrease in the age differences in the obesity OR after 2009 (Figure 1(b)).

The results from our analysis show that the prevalence of obesity is higher in females and the difference by sex is steadily decreasing (Figure 1(c)). Pregnancy and menopause are the significant factors in the development of obesity for many women. Some studies showed that the average woman gains 1-2.5 kg during menopausal transition [34] and more than $10 \mathrm{~kg}$ after delivery [35]. Flegal et al. [36] showed significant increasing linear trends among women for overall obesity but not among men in the United Sates, between 2005 and 2014. The one factor most consistently related to weight gain is physical activity. Changes in family work patterns may be concerned. Both men and women are busy and have less time to spend on health behaviors and reduced time for cooking, and meals eaten away from home have contributed to diets becoming increasingly high in fat and energy.

Our findings also show a continuing decrease in the regional differences in the prevalence of obesity (Figure 1(d)), 

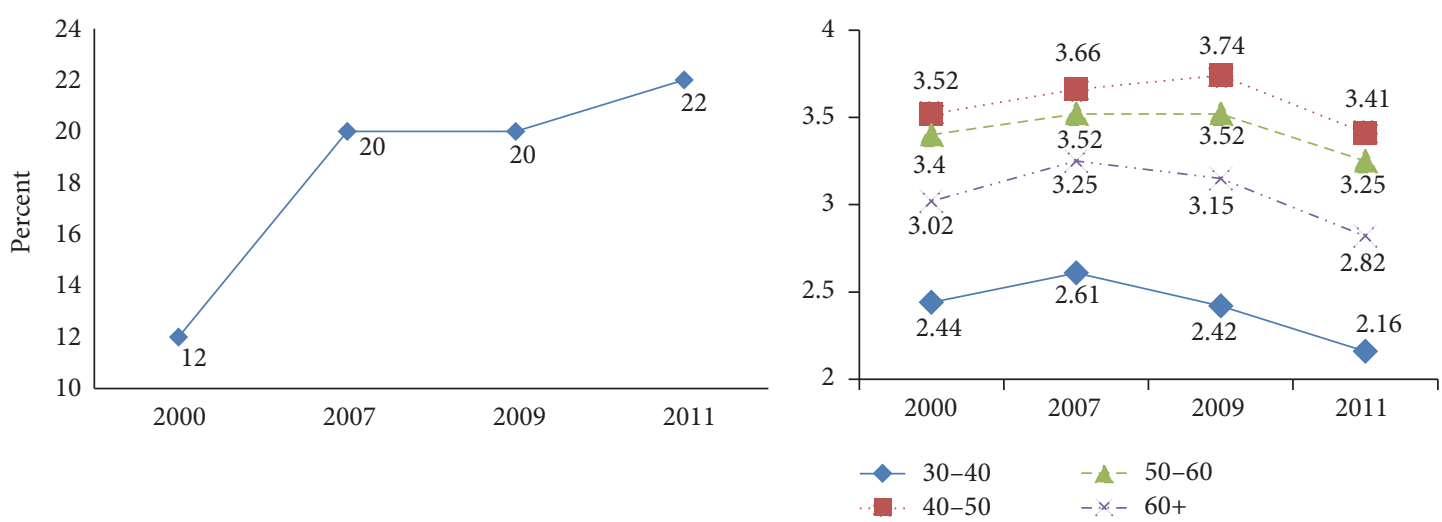

(a) Prevalence of obesity

(b) Adjusted obesity odds ratio for age (reference: $20-30$ years)

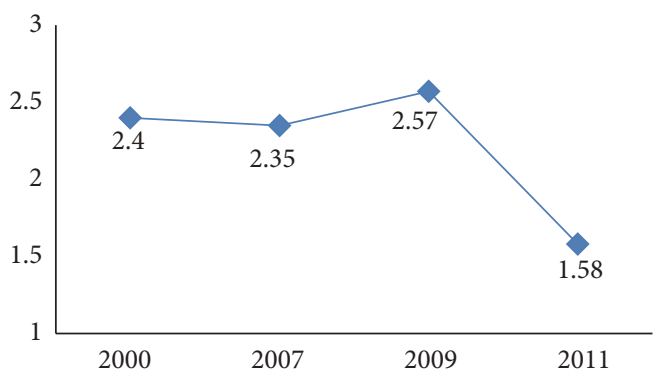

(c) Adjusted obesity odds ratio for women

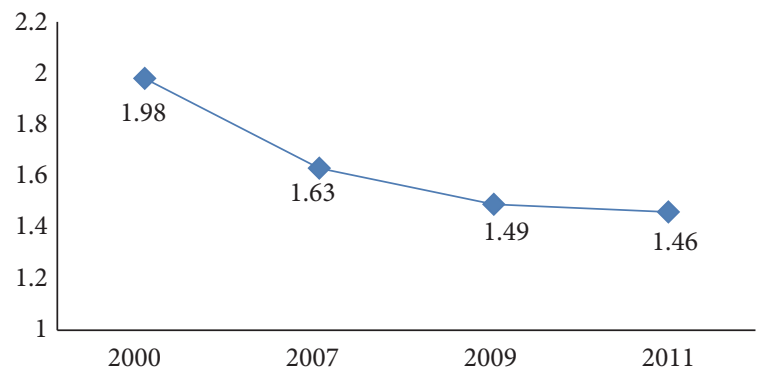

(d) Adjusted obesity odds ratio for urban adults

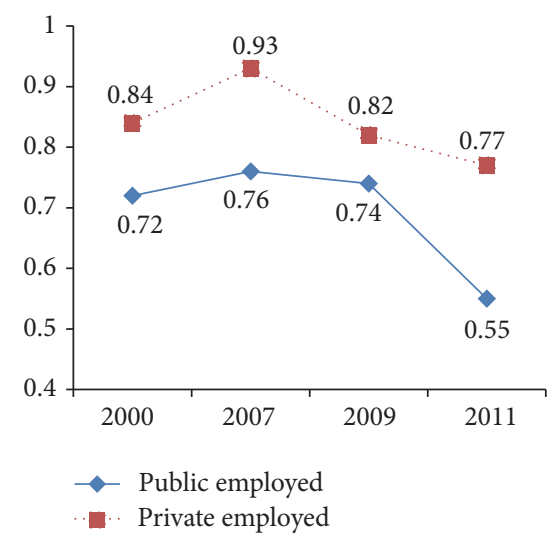

(e) Adjusted obesity odds ratio for employment status (reference: others)

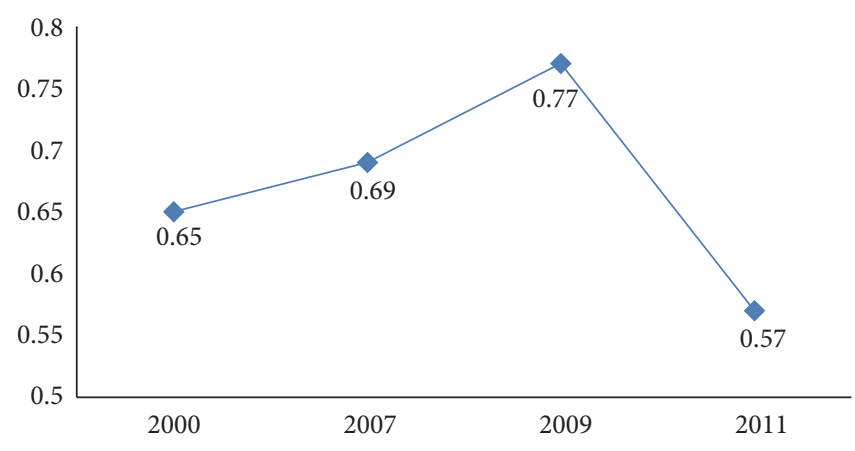

(f) Adjusted obesity odds ratio for smokers

FIGURE 1: Prevalence of obesity (a) and association with some factors (b-f) by using QIF method, national surveys, $2000-2011$.

although the prevalence of obesity was higher in urban areas, results similar to findings reported in some studies that have shown that those who lived in rural areas had a lower risk of becoming obese [37]. Differences in the prevalence of obesity across places of residence may be dependent on whether developed or developing countries are studied [18]. Some studies show that, in developing countries, urban residents are taller, are heavier, and have a higher BMI than those who live in rural areas [38]. In rural areas of the developing world, people make major contributions to agricultural production, so the opportunities for outdoor activities and an active lifestyle are likely to be greater in urban environments.
The prevalence of obesity rose according to level of employment. The prevalence in public employed level was lower than the other levels. Our findings also show that the difference by employment level is steadily increasing (Figure 1(e)). This difference may be due to physical activity. It is also possible that there is more discrimination against the obese or obese people may end up in lower status jobs through stronger selective processes in Iran. Obesity may be more acceptable among unemployed people. It is commonly believed that overweight and obese people are lazy and gluttonous and they lack self-control. Some people believe that an obese person is taking up more space than he or she 
should and a job is often denied because of their weights [39]. Another explanation for the effect of the workforce may involve energy expenditure at work or the structured lifestyle that active people impose.

Our results are consistent with the founding of some studies that smoking is related to decreased obesity odds among adults [40]. From 2000 to 2009, this difference was decreasing, whereas this difference continues to rise after 2009 (Figure 1(f)). Biological and psychological factors could be related to the effect of smoking on obesity. Studies found that nicotine-induced decreases in appetite are due to hypothalamic melanocortin system [41, 42]. Another study showed that some tobacco companies had added some substances into their cigarette in order to reduce smokers' appetite [43]. An increase of energy expenditure while smoking, both in resting and in light physical activity conditions, may relate to lower prevalence of obesity in smokers [24]. Loos [44] entered a new era of gene discovery for obesity.

The use of cross-sectional surveys is a limitation of this study. So we were unable to draw conclusions regarding the causal association between factors and obesity. Longitudinal data would provide a more valid and reliable estimate of the prevalence of obesity and related factors. A further limitation is that physical activity and marital status were not used in our investigation.

The use of large, nationally representative data sets is a major strength of our study. Because people tend to underestimate their weight and overestimate their height [45], height and weight were actually measured rather than self-reported.

\section{Conclusions}

While obesity prevalence generally increased in both sexes, all ages, all employment, residence, and smoking levels, it seems to have changes in obesity ORs since 2000. Because obesity is one of the main risk factors for many diseases, awareness of the differences by factors allows development of targets for prevention and early intervention.

\section{Abbreviations}

BMI: $\quad$ Body mass index

OR: Odds ratio

NHSI: National Health Survey in Iran

WDICH: Without dichotomizing

DICH: Dichotomizing.

\section{Ethical Approval}

This study was approved by the Ethics Committee of the University of Social Welfare and Rehabilitation Sciences.

\section{Competing Interests}

The authors declared no competing interests.

\section{Acknowledgments}

The authors acknowledge the Center for Diseases Control for its data, coordinated at the Iranian Ministry of Health and Medical Education. They are grateful to all the participants of this study.

\section{References}

[1] C. J. Lavie, R. V. Milani, and H. O. Ventura, "Obesity and cardiovascular disease: risk factor, paradox, and impact of weight loss," Journal of the American College of Cardiology, vol. 53, no. 21, pp. 1925-1932, 2009.

[2] M. Bastien, P. Poirier, I. Lemieux, and J.-P. Després, "Overview of epidemiology and contribution of obesity to cardiovascular disease," Progress in Cardiovascular Diseases, vol. 56, no. 4, pp. 369-381, 2014.

[3] M. A. Alpert, J. Omran, A. Mehra, and S. Ardhanari, "Impact of obesity and weight loss on cardiac performance and morphology in adults," Progress in Cardiovascular Diseases, vol. 56, no. 4, pp. 391-400, 2014.

[4] F. B. Ortega, C. J. Lavie, and S. N. Blair, "Obesity and cardiovascular disease," Circulation Research, vol. 118, no. 11, pp. 17521770, 2016.

[5] P. Koh-Banerjee, Y. Wang, F. B. Hu, D. Spiegelman, W. C. Willett, and E. B. Rimm, "Changes in body weight and body fat distribution as risk factors for clinical diabetes in US men," American Journal of Epidemiology, vol. 159, no. 12, pp. 1150-1159, 2004.

[6] J. Zicha, "Diltiazem VUFB (Diacordin Spofa) in the treatment of arterial hypertension]," Vnitrní Lékarství, vol. 35, no. 5, pp. 439-444, 1989.

[7] S. A. Oliveria, D. T. Felson, P. A. Cirillo, J. I. Reed, and A. M. Walker, "Body weight, body mass index, and incident symptomatic osteoarthritis of the hand, hip, and knee," Epidemiology, vol. 10, no. 2, pp. 161-166, 1999.

[8] E. S. Ford, “The epidemiology of obesity and asthma," Journal of Allergy and Clinical Immunology, vol. 115, no. 5, pp. 897-910, 2005.

[9] H. J. Milionis, M. Florentin, and S. Giannopoulos, "Metabolic syndrome and Alzheimer's disease: a link to a vascular hypothesis?" CNS Spectrums, vol. 13, no. 7, pp. 606-613, 2008.

[10] M. Heo, A. Pietrobelli, D. Wang, S. B. Heymsfield, and M. S. Faith, "Obesity and functional impairment: influence of comorbidity, joint pain, and mental health," Obesity, vol. 18, no. 10, pp. 2030-2038, 2010.

[11] The Global BMI Mortality Collaboration, "Body-mass index and all-cause mortality: individual-participant-data metaanalysis of 239 prospective studies in four continents," The Lancet, vol. 388, no. 10046, pp. 776-786, 2016.

[12] http://www.who.int/mediacentre/factsheets/fs311/en/.

[13] C. L. Ogden, M. D. Carroll, C. D. Fryar, and K. M. Flegal, "Prevalence of obesity among adults and youth: United States, 2011-2014,” NCHS Data Brief 219, 2015.

[14] L. K. Twells, D. M. Gregory, J. Reddigan, and W. K. Midodzi, "Current and predicted prevalence of obesity in Canada: a trend analysis," CMAJ Open, vol. 2, no. 1, pp. E18-E26, 2014.

[15] https://www.noo.org.uk/NOO_about_obesity/adult_obesity/UK _prevalence_and_trends.

[16] J. A. Greenberg, "Obesity and early mortality in the United States," Obesity, vol. 21, no. 2, pp. 405-412, 2013. 
[17] S. Sarlio-Lähteenkorva, K. Silventoinen, and E. Lahelma, "Relative weight and income at different levels of socioeconomic status," American Journal of Public Health, vol. 94, no. 3, pp. 468-472, 2004.

[18] M. Neovius and F. Rasmussen, "Place of residence and obesity in 1,578,694 young swedish men between 1969 and 2005," Obesity, vol. 16, no. 3, pp. 671-676, 2008.

[19] A. Sengupta, F. Angeli, T. S. Syamala, P. C. Dagnelie, and C. P. van Schayck, "Overweight and obesity prevalence among Indian women by place of residence and socio-economic status: contrasting patterns from 'underweight states' and 'overweight states' of India," Social Science and Medicine, vol. 138, pp. 161169, 2015.

[20] U. John, M. Hanke, H.-J. Rumpf, and J. R. Thyrian, "Smoking status, cigarettes per day, and their relationship to overweight and obesity among former and current smokers in a national adult general population sample," International Journal of Obesity, vol. 29, no. 10, pp. 1289-1294, 2005.

[21] E. Bakhshi, K. Mohammad, M. R. Eshraghian, and B. Seifi, "Factors related to obesity among Iranian men: results from the National Health Survey," Public Health Nutrition, vol. 13, no. 9, pp. 1389-1394, 2010.

[22] A. Biglarian, B. Seifi, E. Bakhshi et al., "Low back pain prevalence and associated factors in Iranian population: findings from the national health survey," Pain Research and Treatment, vol. 2012, Article ID 653060, 5 pages, 2012.

[23] E. Bakhshi, J. Koohpayehzadeh, B. Seifi et al., "Obesity and related factors in Iran: The STEPS survey, 2011," Iranian Red Crescent Medical Journal, vol. 17, no. 6, Article ID e22479, 2015.

[24] F. Asgari, A. Biglarian, B. Seifi, A. Bakhshi, H. H. Miri, and E. Bakhshi, "Using quadratic inference functions to determine the factors associated with obesity: findings from the STEPS Survey in Iran," Annals of Epidemiology, vol. 23, no. 9, pp. 534-538, 2013.

[25] A. Qu, B. G. Lindsay, and B. Li, "Improving generalised estimating equations using quadratic inference functions," Biometrika, vol. 87, no. 4, pp. 823-836, 2000.

[26] P. X.-K. Song, Z. Jiang, E. Park, and A. Qu, "Quadratic inference functions in marginal models for longitudinal data," Statistics in Medicine, vol. 28, no. 29, pp. 3683-3696, 2009.

[27] A. Qu and R. Z. Li, "Quadratic inference functions for varyingcoefficient models with longitudinal data," Biometrics, vol. 62, no. 2, pp. 379-391, 2006.

[28] I. M. Chapman, "Obesity in old age," Frontiers of Hormone Research, vol. 36, pp. 97-106, 2008.

[29] R. N. Baumgartner, P. M. Stauber, D. McHugh, K. M. Koehler, and P. J. Garry, "Cross-sectional age differences in body composition in persons 60+ years of age," The Journals of Gerontology Series A: Biological Sciences and Medical Sciences, vol. 50, no. 6, pp. M307-M316, 1995.

[30] D. Gallagher, M. Visser, R. E. De Meersman et al., "Appendicular skeletal muscle mass: effects of age, gender, and ethnicity," Journal of Applied Physiology, vol. 83, no. 1, pp. 229-239, 1997.

[31] M. A. Flynn, G. B. Nolph, A. S. Baker, W. M. Martin, and G. Krause, "Total body potassium in aging humans: a longitudinal study," The American Journal of Clinical Nutrition, vol. 50, no. 4, pp. 713-717, 1989.

[32] D. T. Villareal, C. M. Apovian, R. F. Kushner, and S. Klein, "Obesity in older adults: technical review and position statement of the American Society for Nutrition and NAASO, The Obesity Society," The American Journal of Clinical Nutrition, vol. 82, no. 5, pp. 923-934, 2005.
[33] E. Bakhshi, B. Seifi, A. Biglarian, and K. Mohammad, "Factors associated with obesity in Iranian elderly people: results from the national health survey," BMC Research Notes, vol. 4, article 538, 2011.

[34] J. C. Lovejoy, "The influence of sex hormones on obesity across the female life span," Journal of Women's Health, vol. 7, no. 10, pp. 1247-1256, 1998.

[35] B. Abrams, S. L. Altman, and K. E. Pickett, "Pregnancy weight gain: still controversial," The American Journal of Clinical Nutrition, vol. 71, no. 5, supplement, pp. 1233S-1241S, 2000.

[36] K. M. Flegal, D. Kruszon-Moran, M. D. Carroll, C. D. Fryar, and C. L. Ogden, "Trends in obesity among adults in the United States, 2005 to 2014," The Journal of the American Medical Association, vol. 315, no. 21, pp. 2284-2291, 2016.

[37] C. Padez, "Trends in overweight and obesity in Portuguese conscripts from 1986 to 2000 in relation to place of residence and educational level," Public Health, vol. 120, no. 10, pp. $946-$ 952, 2006.

[38] C. A. Monteiro, L. Mondini, A. L. M. de Souza, and B. M. Popkin, "The nutrition transition in Brazil," European Journal of Clinical Nutrition, vol. 49, no. 2, pp. 105-113, 1995.

[39] E. Bakhshi, B. Seifi, A. Biglarian, and K. Mohammad, "Changes in body mass index across age groups in Iranian women: results from the national health survey," Journal of Nutrition and Metabolism, vol. 2012, Article ID 848403, 9 pages, 2012.

[40] R. W. Jeffery, M. T. McGuire, and S. A. French, "Prevalence and correlates of large weight gains and losses," International Journal of Obesity, vol. 26, no. 7, pp. 969-972, 2002.

[41] Y. S. Mineur, A. Abizaid, Y. Rao et al., "Nicotine decreases food intake through activation of POMC neurons," Science, vol. 332, no. 6035, pp. 1330-1332, 2011.

[42] M. R. Picciotto and Y. S. Mineur, "Nicotine, food intake, and activation of POMC neurons," Neuropsychopharmacology, vol. 38, no. 1, p. 245, 2013.

[43] S. Gonseth, I. Jacot-Sadowski, P. A. Diethelm, V. Barras, and J. Cornuz, "The tobacco industry's past role in weight control related to smoking," European Journal of Public Health, vol. 22, no. 2, pp. 234-237, 2011.

[44] R. J. F. Loos, "Recent progress in the genetics of common obesity," British Journal of Clinical Pharmacology, vol. 68, no. 6 , pp. 811-829, 2009.

[45] S. C. Gorber, M. Tremblay, D. Moher, and B. Gorber, "A comparison of direct vs. self-report measures for assessing height, weight and body mass index: a systematic review," Obesity Reviews, vol. 8, no. 4, pp. 307-326, 2007. 


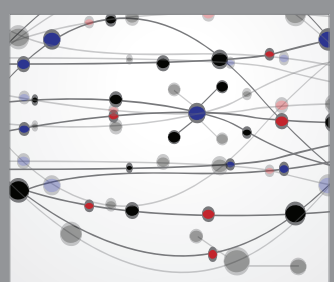

The Scientific World Journal
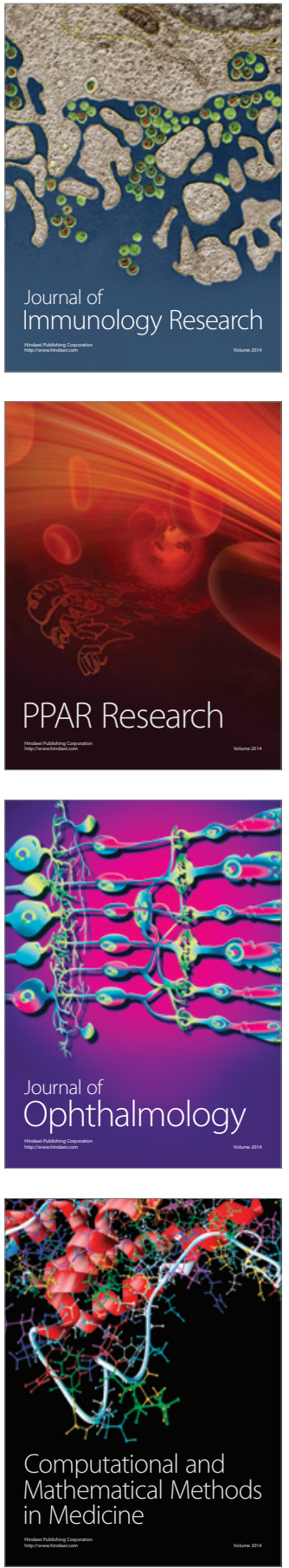

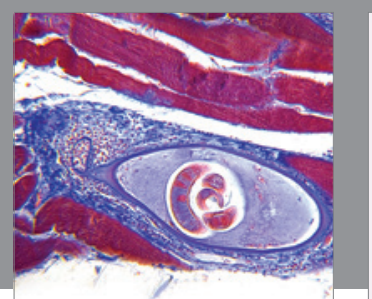

Gastroenterology Research and Practice

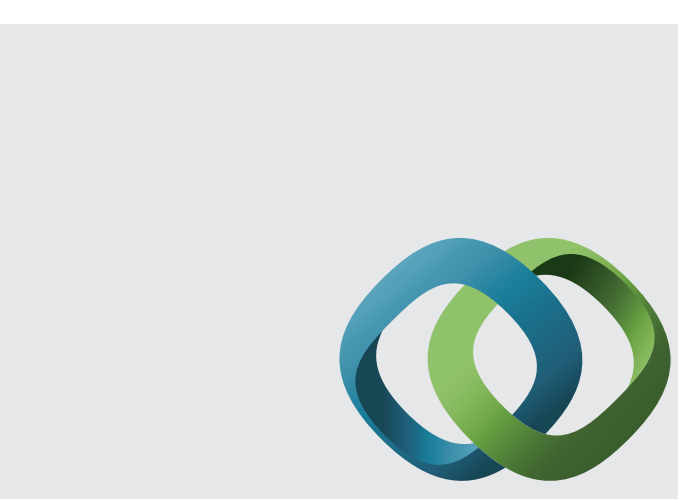

\section{Hindawi}

Submit your manuscripts at

http://www.hindawi.com
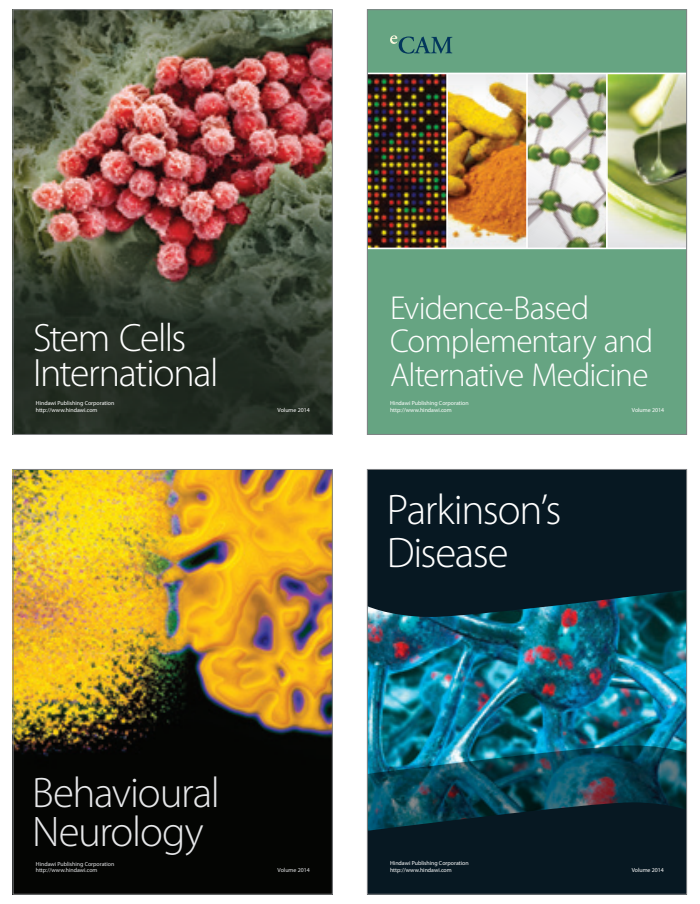
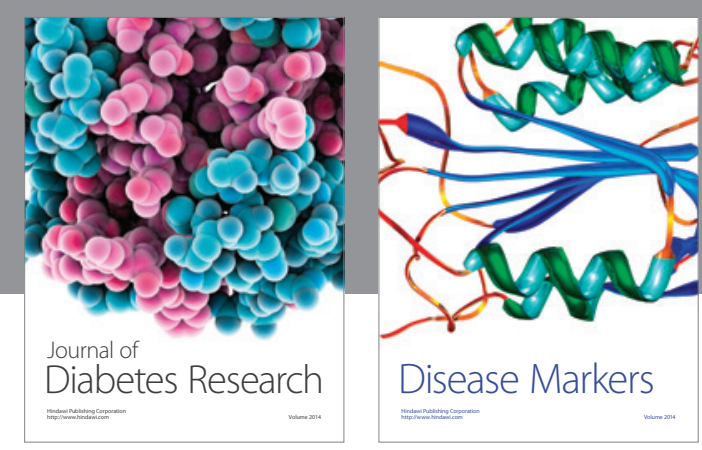

Disease Markers
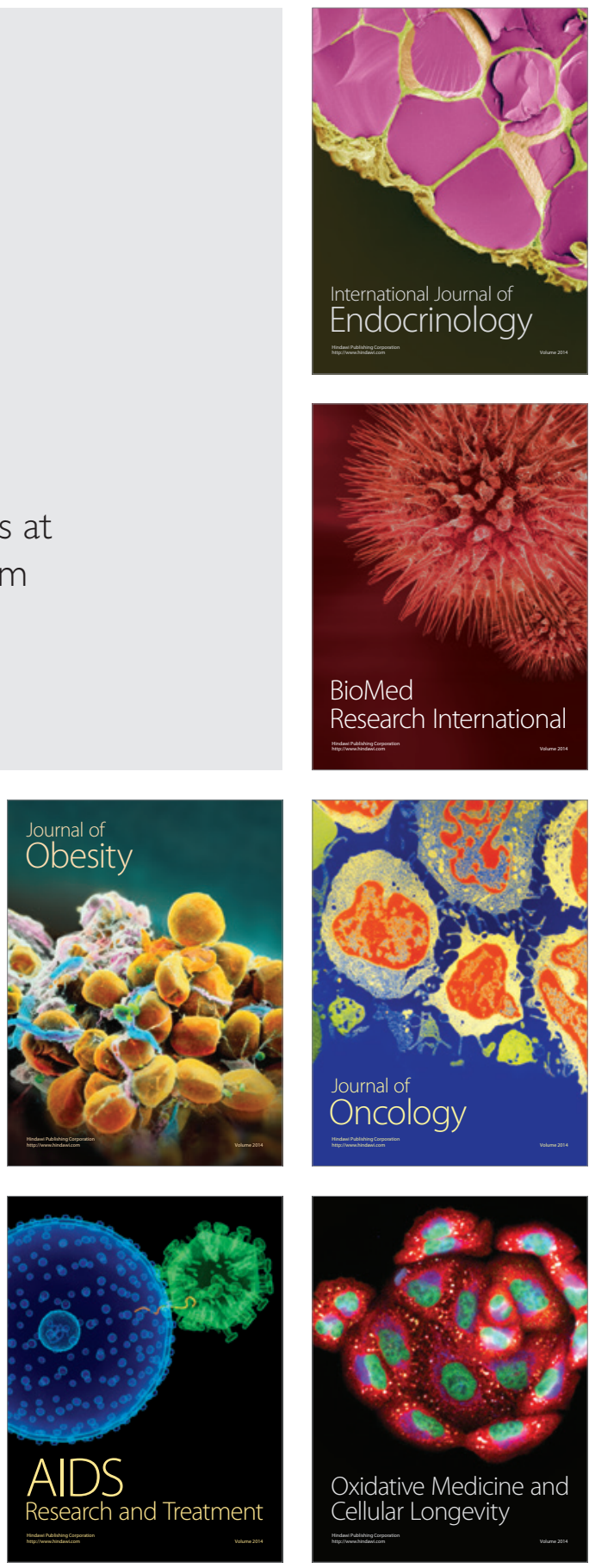